www.mdpi.com/journal/socsci

Project Report

\title{
Intercorrelations of Intimacy and Identity Dating Goals with Relationship Behaviors and Satisfaction among Young Heterosexual Couples
}

\section{Melanie J. Zimmer-Gembeck ${ }^{1}{ }^{1}$, Vanessa Arnhold ${ }^{1}$ and Jennifer Connolly ${ }^{2}$}

1 School of Applied Psychology and Griffith Health Institute, Behavioural Basis of Health, Griffith University, Parklands Drive, G40, Southport QLD 4222, Australia;

E-Mail: vanessa.arnhold@griffithuni.edu.au

2 Department of Psychology, York University, 4700 Keele Street, Toronto, Ontario M3J 1P3, Canada; E-Mail: connolly@yorku.ca

* Author to whom correspondence should be addressed; E-Mail: m.zimmer-gembeck@griffith.edu.au; Tel.: +61-7-567-890-85; Fax: +61-7-567-882-91.

Received: 26 November 2013; in revised form: 20 January 2014 / Accepted: 22 January 2014 / Published: 29 January 2014

\begin{abstract}
Goals indicate what individuals are working towards in their present lives and what they want to achieve or avoid. In this study of 87 young, unmarried couples (age 17 to 25 years), intimacy and identity dating goals were assessed to investigate couple similarity in goals, associations between personal goals and relationship behaviors, and whether goals and behavior were associated with relationship satisfaction. Couples were similar in their intimacy goals but not their identity goals. As expected, intimacy goals were associated with behaviors when reported by the partner, including greater warmth, autonomy support and structure, and less rejection. One's own intimacy goals and the positive behaviors of one's partner, but not one's own identity goals or the goals of the partner, were uniquely associated with relationship satisfaction. The findings suggest that individual differences in dating goals are relevant to understanding how young people behave with their partners, and why some individuals are more or less satisfied with their relationships.
\end{abstract}

Keywords: dating; goals; intimacy; identity; romantic relationships; satisfaction; partner behavior 


\section{Introduction}

Although almost all adolescents and young adults have romantic interests and are involved in romantic relationships [1-4], there is great variability in the goals that young people express when asked about the purpose of their romantic pursuits [2,5-7]. For example, in research on dating goals, some of the expressed reasons for dating have been intimacy and identity [7-9]. In other research, young people express goals for sexual pleasure and gaining social status $[7,8,10]$. However, consistent with the developmental tasks of adolescence and early adulthood, when goals for intimacy, identity, sex and social status are assessed, intimacy and identity are the two most prominent goals for dating during adolescence and early adulthood [11]. The dating goal of intimacy involves dating to fulfill a general desire for emotional attachment, mutual dependence and the sharing of thoughts and feelings within an intimate setting [8]. The dating goal of identity involves placing importance on self-exploration and identity formation as part of the dating process [11]. In addition, previous research has shown that intimacy and identity dating goals only have a small correlation with each other in samples of older adolescents and young adults; for example, intimacy and identity dating goals had a small correlation of $r=.12$ in one previous study of 370 Australians aged 16 to 25 [11].

Moreover, considering the results of the seven past studies of dating goals [7,9,11-16], greater endorsement of intimacy dating goals has been associated with elevated relationship satisfaction [12-16], and both intimacy and identity dating goals have been found to relevant for relationship and sexual behavior [7-9,11], as well as for behaviors outside the social domain [7]. Nevertheless, much remains to be known about whether dating goals play roles in romantic partner behaviors and overall relationship satisfaction, and nothing is known about the co-occurrence of dating goals within couple relationships. In the present study of young couples' dating goals, the purpose was to examine the similarity in intimacy and identity dating goals within couples and to investigate whether goals were associated with particular romantic relationship behaviors (as reported by the partner) and general relationship satisfaction.

\subsection{Goal Similarity within Couples}

The first question addressed in the current study was whether goal similarity would be found within couples. An important component for initiating a dating relationship is choosing a partner who has characteristics, needs and goals that aid in the fulfillment of one's personal goals [17,18]. Motivational and life task theories highlight individuals' goals as important organizers of life tasks and pursuits [19-22]. Moreover, self-verification theory [23] suggests that individuals seek partners who are consistent with how we see ourselves. In line with these theories, dating goals have been described as personal factors that can influence the choice of romantic partners and the experiences and satisfaction that is found in relationships [24]. In particular, theory suggests that individuals will navigate towards romantic partners who will aid in their own goal pursuits, and when this occurs, life and relationship satisfaction should be enhanced [12,25-27].

Desiring and engaging in reciprocal self-disclosure and interdependence with a partner necessitates a receptive partner [13]. Therefore, individuals with a strong focus on intimacy should favor partners with predominant intimacy dating goals. Given, the centrality of intimacy to couple relationships, 
similarity in intimacy dating goals should be high. In the same way, those with a strong focus on identity goals might favor partners with predominant identity dating goals. However, the similarity between identify dating goals might be more modest, given that complementarity might also be relevant for identity goals with one partner more or less willing to support the other's stronger identity goals.

\subsection{Dating Goals and Romantic Relationship Behavior}

Goals indicate what individuals are working towards in their present lives and what they want to achieve or avoid [28]. Goals imply that individuals are active participants within their social environments, engaging in tasks that appeal to them and striving towards individual, as well as interpersonal, congruency between goals and behavior [29,30]. Theorists of personal-goal research have noted the importance of differentiating cognitive, affective and behavioral components in understanding motivations and subjective well-being [28,31]. Individuals will often develop schemas and cognitive strategies to attain life goals, converting these strategies into goal-directed behaviors [19,32]. In fact, research studies have found that individuals who report greater well-being are likely to pursue goals that are meaningful and rewarding, incite positive expectations, involve autotelic motivations, receive support from others and meet minimal conflicts with competing tasks $[31,33]$.

Although there have been few studies of dating goals and how they may be linked to romantic relationship behavior, individuals have been found to be more likely to follow through on intentions of safer sex when education regarding healthy dating situations was tailored to their dating goals. Moreover, individuals with more intimacy goals favored open communication regarding condom use more than those with mainly identity goals who favored self-sufficiency [14]. In a second study of adolescents and young adults, individuals who had more intimacy goals engaged in more affiliative behaviors and those with identity goals engaged more in behaviors focused on independent achievement pursuits [7]. Thus, these findings suggest that intimacy goals would be associated with more positive relationship behaviors, such as warmth, involvement and support. To date, however, no research has examined whether different dating goals are associated with such relationships behaviors. To examine this in the current study, six relationship behaviors were investigated.

Based on theory, we measured six behaviors that reflected close relationship interactions associated with individual's psychological needs for relatedness, autonomy and competence [29,30,34-36]. Relatedness is most closely associated with intimacy goals, and refers to a sense of belonging, security and connectedness to others [30,37,38]. Autonomy is more closely associated with identity goals and refers to organized, integrated and volitional action or "the experience of one's actions as self-endorsed" ([38], p. 146; [39]). Competence is defined as feeling effective in interactions within the surrounding environment $[14,40]$. There are three relationship behaviors that are theoretically supportive of these needs, including warmth (involvement and affection), autonomy support (independent action and decision making), and structure (consistent and reliable). There are also three relationship behaviors are undermine these three needs, including rejection (hostile and critical), coercion (demanding and controlling), and chaos (erratic and unpredictable). All were considered as potential correlates of intimacy and identity dating goals in the current study.

Evidence suggests that the associations between intimacy dating goals and one's own relationship behaviors should be numerous and rather nonspecific. Intimacy-focused individuals are found to be 
warmer and more understanding partners, and they engage in more self-disclosure and interdependence [41]. Moreover, in a separate study, individuals who reported relatively more intimacy dating goals were more likely to tailor their dating lives so as to spend more time alone with partners and report more self-disclosure, dependence, partner support and positive thoughts about their partner [15]. These findings imply that those with greater intimacy dating goals would be elevated in all of the positive relationship behaviors and engage in fewer of all of the negative behaviors.

In contrast to intimacy goals and once the association of intimacy goals with relationship behavior is accounted for, theory suggests that the associations of identity dating goals with behaviors should be isolated to the positive relationship behavior of autonomy support and the negative relationship behavior of coercion. These specific associations between identity dating goals and autonomy supportive/less coercive behavior links a personal focus on independent goals and personal identity achievement with relationship behaviors that would support such pursuits in the partner, just as has been proposed in Self-Determination Theory [30,42] and Cognitive Evaluation Theory (CET) [42], a sub-theory of SDT. These theories have identified autonomy support as particularly important to promoting self-development [30,39]. Conversely, coercion by close others has been proposed to undermine independent goal pursuit. In addition, an association between identity dating goals and independent goal pursuit, but not between intimacy dating goals and independent goal pursuit, was reported in one previous study [7]. This suggests that identity dating goals would have links to the relationship behaviors of autonomy support and coercion only, with identity goals associated with more autonomy supportive and less coercive behavior

\subsection{Dating Goals and Relationship Satisfaction}

Theorists and researchers have emphasized the pursuit of intimacy in close relationships and its association with relationship satisfaction, a common marker of positive behavior and well-being $[43,44]$. Such an association between intimacy pursuits and relationship satisfaction has been confirmed when focusing on dating goals. Individuals who report more intimacy dating goals reported heightened romantic relationship satisfaction $[15,16]$. In contrast to the emphasis on dating as the pursuit of intimacy, some individuals may also express dating goals that pertain to self-exploration and the maintenance of an identity that is apart from the relationship [14]. Both intimacy and identity goals may be desirable and positive for relationship functioning and satisfaction.

All individuals are expected to have psychological needs for both relatedness and autonomy, and, thus, individuals and relationships can benefit from a focus on both intimacy and identity concerns [30,44-46]. Intimacy implies a focus on maintaining closeness but identity goals could also serve to balance intimacy with autonomy allowing the development of relationships that are more balanced. The importance of intimacy and identity goals may be particularly important to consider in the relationships of young adult couples because they are at the age when intimacy and identity development are salient concerns and life tasks $[14,16,47-50]$. Yet, no previous study has examined whether intimacy and identity dating goals enhance relationship satisfaction. 


\subsection{Study Aims, Hypotheses, and Overview of the Analyses}

Couples participated in the present study. Thus, each member of the participating couples reported their own dating goals and relationship satisfaction, as well as the relationship behaviors of the partner. Throughout all analyses, multilevel modeling was used to take into account the nested nature of the person data (level 1) within couples (level 2). Our three aims were to examine similarity in dating goals within couples; whether dating goals were associated with one's own relationship behaviors; and whether one's own goals, and the goals and behaviors of the partner, were associated with relationship satisfaction. Regarding the first aim, we expected to find significant similarity in dating goals within couples. Regarding the second aim, it was expected that intimacy dating goals would be associated with one's own elevated positive relationship behavior and less negative relationship behavior. We also expected that young people who expressed more identity goals would be more autonomy supportive and less coercive.

Regarding the third aim, we hypothesized that elevated intimacy and identity goals would be associated with greater personal relationship satisfaction. In these analyses, we also considered the dating goals and relationship behaviors of the partner, and expected that more positive behaviors and fewer negative behaviors would be associated with greater relationship satisfaction (as has been found in much previous research) [51,52], and that the partner's intimacy goals would be uniquely associated with greater relationship satisfaction.

\section{Method}

\subsection{Participants}

The participants were 87 unmarried young couples aged 17 to $25\left(M_{\mathrm{age}}=20.5, S D=2.4\right)$. Participants were predominantly Caucasian (83\%) or reported Asian descent $(12 \%)$, and lived with their parents $(42 \%)$, with just their partners $(12 \%)$, with their partner and other roommates $(25 \%)$, or with roommates only or alone (21\%). The average relationship length was 19 months $(M=18.9$, $S D=17.5)$. Most participants were full time $(31.5 \%)$ or part-time $(53.2 \%)$ students. Overall, $10 \%$ worked full-time and $57 \%$ worked part-time. Although same-sex couples were not excluded, all couples were heterosexual.

\subsection{Materials}

\subsubsection{Dating Goals}

Intimacy and identity dating goals were measured using the Social Dating Goals Scale-Revised (SDGS-R) [11]. The SDGS-R intimacy and identity subscales contains 12-items with response options ranging from 1 (disagree strongly) to 5 (agree strongly). Each item begins with, "In my dating relationships, I try to" and includes items such as "Date people with whom I might fall in love with" (intimacy) and "Maintain a strong sense of independence" (identity). Items were averaged to form composite scores for intimacy dating goals and identity dating goals. In the current study Cronbach's $\alpha$ was .74 for intimacy and .71 for identity goals. Intimacy and identity goals were not significantly correlated, $r=-.07$. 


\subsubsection{Relationship Satisfaction}

Relationship satisfaction was measured using seven items from the Relationship Assessment Scale [43]. Five items were positively valenced ("In general, how satisfied are you with your relationship?) and two items were negatively valenced ("How much do you wish you hadn't gotten into this relationship?). The item responses ranged from 1 (not at all) to 5 (extremely). After reverse scoring appropriate items, items were averaged. Higher scores indicated greater relationship satisfaction. Cronbach's $\alpha$ was .78.

\subsubsection{Romantic Relationship Behavior}

The 30-item Partner Behaviors as Social Context (PBSC) was used to assess partner's positive and negative relationship behaviors [36]. Three subscales (five items each) assessed positive romantic behaviors of warmth, autonomy support, and structure. Partner warmth was defined as the provision of affection and love, (e.g., "My partner shows me he/she loves me"), autonomy support was defined support and respect for choice and personal decision-making (e.g., "My partner supports my interests"), and structure was defined as consistency and reliability (e.g., "My partner follows through on things). Three subscales ( 5 items each) assessed negative partner behaviors including rejection, coercion, and chaos. Rejection was defined as cold, detached or critical behaviors, (e.g., "My partner can make me feel like I'm not wanted"); coercion was defined as excessively demanding and controlling behaviors, (e.g., "My partner tries to control me") and chaos was defined as unpredictable and unreliable behaviors, (e.g., "I never know what my partner will do next"). Response options ranged from 1 (not at all true) to 6 (very true). Items on each subscale were averaged to form the six composite scores. For each subscale, higher scores indicated more warmth, autonomy support, structure, rejection, coercion, and chaos. In the current study, Cronbach's $\alpha$ were .59 for structure, .67 for rejection, .68 for chaos, .72 for warmth, .76 for coercion, and .82 for autonomy support.

\subsection{Procedure}

The Human Ethics Review Committee approved the study prior to initiating data collection. Data were collected during the week prior to the start of the first semester when many young people are on campus at market booths and orientation sessions. This week draws both students and nonstudents to the campus. Couples were approached at various locations, such as the library, book store, cafeteria, and university bar. Participants identified as dating couples were then asked questions based on inclusion criteria, which included questions about age and relationship duration. Dating couples that met the criteria ( 25 years or less and in a relationship of length 1 month or longer) were then asked to complete questionnaires separately. The questionnaires took approximately 20 minutes to complete and participants were provided with chocolate upon completion.

All participants were provided with an information sheet detailing the purpose of the study and the assurance of complete confidentiality. No identifying information was collected, and each couple was given the same identification number, which was recorded on the cover sheet of their questionnaires prior to completion. 


\section{Results}

\subsection{Similarity in Goals, and Associations between Goals and Relationship Satisfaction}

Table 1 presents the descriptive statistics for all measured variables. Table 1 also provides intraclass correlations (to take into account the dyad unit) between relationship satisfaction, goals, and behaviors within couples; $r$ 's ranged from .10 to .45 , and the largest correlation was for relationship satisfaction, $r=.45$. As anticipated, intimacy dating goals were correlated (i.e., similar in relative ranking) within couples, $r=.31, p<.01$. Identity dating goals were not significantly correlated within couples, $r=.10$.

Table 1. Means and Standard Deviations for all Measures, and Partners' Similarity ( $N=87$ couples).

\begin{tabular}{lccc}
\hline Variables & $\boldsymbol{M}$ & $\boldsymbol{S D}$ & Couple similarity, ICC \\
\hline Relationship satisfaction, SR & 4.53 & 0.53 & $.45^{* *}$ \\
Intimacy goals, SR & 4.31 & 0.49 & $.31 * *$ \\
Identity goals, SR & 4.39 & 0.44 & .10 \\
Warmth, PR & 5.24 & 0.73 & $.26 *$ \\
Autonomy support, PR & 4.98 & 0.75 & $.41 * *$ \\
Structure, PR & 4.93 & 0.72 & $.30 * *$ \\
Rejection, PR & 1.86 & 0.76 & $.38^{* *}$ \\
Coercion, PR & 2.44 & 1.00 & $.32 * *$ \\
Chaos, PR & 2.01 & 0.78 & .21 \\
\hline
\end{tabular}

$* p<.05 . * * p<.01$. Note: ICC = Intraclass correlation; SR = Self-report; PR = Partner Report; behaviors reported by the partner. For example, warmth for males is male warm behavior as reported by their female partners, and warmth for females is female warm behavior as reported by their male partners.

\subsection{Associations of Partner Relationship Behaviors with Dating Goals}

Table 2 shows the results of six multilevel models, with persons nested within dyads, that examined the unique associations of one's own dating goals with one's own relationship behaviors (reported by romantic partners). As can be seen and, as expected, intimacy goals were associated with one's own behavior, including more positive and less negative behaviors. Young people who reported more intimacy goals were described by their partners as warmer, more structured, and less rejecting. Moreover, as anticipated, young people who reported more identity goals were described by their partners as more autonomy supportive and less coercive.

Table 2. Results of a Multilevel Models Testing Associations of One's Own Relationship Behaviors (as Reported by the Partner) with One's Own Dating Goals ( $N=87$ couples).

\begin{tabular}{lrr}
\hline Independent variables & $\boldsymbol{B}(\boldsymbol{S E})$ & $\boldsymbol{p}$ \\
\hline Model $1 \mathrm{DV}=$ Warmth, PR & & \\
Intimacy goals & $.45(.11)$ & $<.01$ \\
Identity goals & $.10(.12)$ & .43 \\
Model 2 DV = Autonomy support, PR & & \\
Intimacy goals & $.18(.11)$ & .11 \\
Identity goals & $.27(.13)$ & $<.05$ \\
\hline
\end{tabular}


Table 2. Cont.

\begin{tabular}{lrr}
\hline Independent variables & $\boldsymbol{B}(\boldsymbol{S E})$ & $\boldsymbol{p}$ \\
\hline Model 3 DV = Structure, PR & $.28(.11)$ & $<.05$ \\
$\quad$ Intimacy goals & $.15(.12)$ & .23 \\
$\quad$ Identity goals & & \\
Model 4 DV = Rejection, PR & $-.22(.12)$ & $<.05$ \\
$\quad$ Intimacy goals & $-.07(.13)$ & .58 \\
Identity goals & & \\
Model 5 DV = Coercion, PR & $.05(.16)$ & .77 \\
$\quad$ Intimacy goals & $-.32(.17)$ & $<.05$ \\
Identity goals & & \\
Model 6 DV = Chaos, PR & $-.22(.12)$ & .08 \\
Intimacy goals & $.00(.13)$ & .98 \\
Identity goals &
\end{tabular}

Note: DV = dependent variables; PR $=$ partner reported. Because age and relationship length were not associated with any other measures, they were not controlled for in this model.

\subsection{Associations of Goals and Behaviors with Relationship Satisfaction}

A multilevel model, with persons nested within dyads, was estimated to examine the unique associations of self-reported dating goals, behaviors exhibited by one's partner, and the partner's dating goals with personal relationship satisfaction. Because of the sample size, we did not examine each of the partner behaviors in this model. Instead, we formed global scores for positive and negative partner behaviors by summing appropriate subscale scores. Thus, we summed warmth, autonomy support and structure to form a composite of positive behavior. We summed rejection, coercion and chaos to form a composite of negative behavior. The results showed that personal intimacy dating goals and partners' positive relationship behaviors, but not partners' dating goals or negative relationship behaviors, were associated with greater relationship satisfaction (see Table 3). We also conducted a further analysis to examine whether the interaction between one's own intimacy goals and the partner's intimacy dating goals were each associated with relationship satisfaction. We reasoned that having two partners with high intimacy goals might yield even greater relationship satisfaction. However, the interaction was not significant.

Table 3. Results of a Multilevel Model Testing Associations of One's Own Relationship Satisfaction with the Dating Goals of Each Partner and Partners' Relationship Behaviors $(N=87$ couples $)$.

\begin{tabular}{lrr}
\hline Independent variables & $\boldsymbol{B}(\boldsymbol{S E})$ & \multicolumn{1}{c}{$\boldsymbol{p}$} \\
\hline Own intimacy goals & $.21(.06)$ & $<.01$ \\
Own identity goals & $-.09(.06)$ & .17 \\
Partner's intimacy goals & $-.03(.05)$ & .53 \\
Partner's identity goals & $.05(.05)$ & .33 \\
Partner's positive behavior & $.19(.02)$ & $<.01$ \\
Partner's negative behavior & $-.01(.01)$ & .70 \\
\hline
\end{tabular}

Note: The dependent variable was one's own relationship satisfaction. Positive behavior included warmth, autonomy support and structure. Negative behavior included rejection, coercion, and chaos. Because age and relationship length were not associated with any other measures, they were not controlled for in this model. 


\section{Discussion}

Extending past research that has identified variability in dating goals among young people [7,9,11], the present study was the first to examine dating goals, as well as six relationship behaviors and relationship satisfaction, within young dating couples. The findings show that there is significant similarity within couples in their intimacy dating goals, most of their relationship behaviors, and their relationship satisfaction. In addition, as expected, both intimacy and identity dating goals covary with particular relationship behaviors in systematic ways. Finally, one's own dating goals and positive relationship behaviors of the partner were each uniquely associated with personal relationship satisfaction, showing for the first time how one's own intimacy dating goals have a unique role in promoting relationship satisfaction above and beyond the behaviors of one's partner.

\subsection{Similarity in Goals and Behaviors}

The first aim of this study was to examine the simple similarity in dating goals within couples. It is widely agreed that one of the factors that promotes relationship formation is similarity in demographic factors, but more relevant to this study, also similarity in attitudes and behaviors [53,54]. These findings provide evidence that couples show significant similarity in their intimacy dating goals, as well as in their behaviors (even when the other partner was the reporter of the behaviors).

Surprisingly, there was no significant couple similarity in identity goals. This finding suggests that a focus on maintaining a personal direction and developing a sense of self as part of dating pursuits can be variable across individuals and within couples. Why might this be the case? One possible explanation is the age of the participants. In late adolescence and early adulthood, identity goals may be more normative because identity (and autonomy) development is a key task of this age group $[39,50,55,56]$. Hence, identity goals may have little substantial influence on satisfaction when a focus on identity development is expected and most relationships are still in formation. Another possibility is that identity goals, regardless of age, have much more to do with pursuits outside the relationship and may only be relevant to satisfaction when they interfere with positive behaviors of warmth and involvement with the partner or prompt behaviors that are perceived as rejecting. However, we found no evidence of interactive effects of goals on relationship satisfaction in this study, but it is possible that these effects might be found among older and more established couples.

\subsection{Dating Goals and Behaviors}

In multiple theories, goals are expected to guide behavior by identifying priorities, values, and impacting life task pursuits [8,30,57-59]. The findings of the current study support such notions. In particular, young people who reported more intimacy dating goals were more likely to be perceived by their partners as warmer and more involved in the relationship, and as more reliable and dependable, and as less rejecting of them. Thus, young people who reported that they pursued dating relationships to have opportunities for emotional closeness and the sharing of intimacy and support seem to be exhibiting the types of behaviors that could promote intimacy and greater satisfaction with their dating relationships.

Regarding identity dating goals, as we had anticipated, these goals were also relevant but had a more localized association with behavior. In particular, identity goals were only associated with more 
autonomy supportive behavior and less coercive behavior, which included items that tapped assisting the partner with personal decision-making, providing support for personal choices, encouraging personal discovery and pursuits. These specific associations between identity dating goals and autonomy supportive/less coercive behavior suggests that a personal focus on independent goals and personal identity achievement seems to translate into behaviors that support such pursuits in the partner, just as has been proposed in Self-Determination Theory [30,42] and Cognitive Evaluation Theory (CET) [42], a sub-theory of SDT. In both theories, individual psychological needs for autonomy are expected to be promoted by social experiences tapped by our measure of autonomy support. Autonomy support is expected to increase self-determination and autonomous regulation of behavior [60]. Our findings suggest that a partner's identity goals could prompt their own autonomy supportive relationship behaviors and reduce their coercive behavior.

\subsection{Goals, Behaviors, and Relationship Satisfaction}

Adding to the above findings, it was also the case that relationship satisfaction was more elevated among participants who reported more intimacy goals and who perceived their partners to be more positive. Over the past few decades, many studies have shown that the relationship behaviors of partners, often called the quality of the relationship, are critical to relationship satisfaction and well-being [50,61-63]. However, no studies have investigated how dating goals may be related to relationship satisfaction within couples or investigated the six different relationship behaviors that we expected to promote (or undermine) relationship satisfaction. Theory suggests that goals and behavior are uniquely important factors that can promote life satisfaction outside the relationship domain [7]. The current study supports this assertion by showing that young people who have more intimacy dating goals also report more satisfaction with their relationships, even after accounting for their perceptions of the positive and negative relationship behaviors of their partners.

It was somewhat surprising that identity goals were not uniquely associated with relationship satisfaction after accounting for relationship behaviors. Yet, identity goals were associated with autonomy supportive behavior. Because identity goals were associated with more autonomy supportive behavior, and autonomy support is one of the positive relationship behaviors associated with relationship satisfaction, it is possible that identity goals are not unimportant to relationship satisfaction. For example, identity goals may have a more indirect role in satisfaction via their implications for behaviors within the relationship.

\subsection{Limitations and Future Directions}

The findings suggest that dating goals and behaviors are associated, and that one's own intimacy goals and the positive relationship behaviors of one's partner, a composite of warmth, structure and autonomy support, are associated with relationship satisfaction. However, these findings were based on cross-sectional data. Hence, we could not establish the direction of these associations. It is anticipated that relationship satisfaction and positive experiences with a partner would also promote changes in dating goals $[7,8]$. Future research will be important to identify changes in goals, behavior, and satisfaction both within and across relationships. 
A second limitation was the number of couples recruited for this study, and the focus on heterosexual couples only. Yet, despite this, most hypotheses were supported, illustrating the medium to strong associations that were found even when reports from different individuals were investigated. Also, there is little reason to expect that the associations between goals, behaviors and satisfaction would differ for same-sex couples, because past research on dating goals and satisfaction outside the dating domain reported almost no differences between young people attracted to the same and young people attracted to the other sex [9].

A third limitation was that we examined couple similarity and associations between variables accounting for the nested data within couples, but we did not focus directly on one partner's influence on the other partner, through the use of Actor-Partner Interdependence Models or other methods [64]. We did not conduct such analyses, because, in order to add substantially to the current results, this meant focusing on some characteristic to distinguish the pairs, such as gender, age or level of goals (e.g., higher or lower than the other partner). Because no previous study has examined dating goals in couples, and because so few previous studies have been conducted on dating goals generally, we believe this study sets the foundation for these types of future research questions to be addressed. For example, future research might address whose goals or behaviors would be more influential in the couple.

Some of the measures used in this study are a final limitation to mention. Three of the six relationship behavior subscales had Cronbach's $\alpha$ 's that were lower than ideal (below .70). This should be kept in mind when considering these results.

In addition to these limitations and the future directions for research we have proposed, a comment about the conceptualization of identity goals is needed. Some items that assessed identity goals could be re-labeled as autonomy goals. Hence, it is important to keep in mind that identity goals may be simultaneously tapping both identity and autonomy tasks of adolescents and young adulthood. We have maintained the label of identity goals to remain consistent with the original conceptualization of this construct $[15,65]$ and the new SDGS-R [11].

\section{Conclusions}

The findings of the present study build confidence in the importance of dating goals for understanding relationship behavior and satisfaction in adolescents and young adults. This study fills a gap in the literature by providing evidence that individual differences in dating goals are relevant to understanding how young people behave with their partners, and why some individuals are more or less satisfied with their relationships. In fact, intimacy goals are uniquely associated with greater satisfaction even after accounting for partners' behaviors in the relationship. More generally, the findings have theoretical and practical implications. Regarding theory, the findings support theory and previous empirical research that has highlighted how individual motivation is one important foundation for social behavior and life satisfaction [7,15,29]. Adding content on dating goals could enhance practice, such as relationship psychoeducational programs, which are designed to help young people with relationship difficulties. By learning about individual differences in goals, young people might be helped to understand differences in relationship preferences and values, and this understanding might assist them to overcome the problems that can follow from relationship conflict and dissolution. 


\section{Acknowledgements}

We express our sincere appreciation to participants for their time. We also are indebted to Shawna Mastro and Julia Rudolph for data collection assistance.

\section{Author Contributions}

Melanie Zimmer-Gembeck conceived of the project, articulated the project aims, conducted all analyses, collected data, and had main responsibility for the writing. Vanessa Arnhold assisted with the project aims, completed literature searching, and assisted with data collection and writing. Jennifer Connolly assisted with the project aims and writing.

\section{Conflicts of Interest}

The authors have no conflict of interest to report.

\section{References}

1. Carver, Karen, Kara Joyner, and John R. Udry. "National estimates of adolescent romantic relationships." In Adolescent Romantic Relationships and Sexual Behavior: Theory, Research, and Practical Implications. Edited by Paul Florsheim. New York: Cambridge University, 2003, pp. 291-329.

2. Collins, W. Andrew, Deborah P. Welsh, and Wyndol Furman. "Adolescent romantic relationships.” Annual Review of Psychology 60 (2009): 631-52.

3. Laursen, Brett, and Vickie A. Williams. "Perceptions of interdependence and closeness in family and peer relationships among adolescents with and without romantic partners." New Directions for Child and Adolescent Development 78 (1997): 3-20.

4. Zimmer-Gembeck, Melanie J. "Stability, change, and individual differences in involvement with friends and romantic partners among adolescent females." Journal of Youth and Adolescence 28 (1999): 419-38.

5. Cantor, Nancy, Michele Acker, and Carol Cook-Flanagan. "Conflict and preoccupation in the intimacy life task." Journal of Personality and Social Psychology 63 (1992): 644-55.

6. Connolly, Jennifer, and Carolyn McIsaac. "Adolescents' explanations for romantic dissolutions: A developmental perspective." Journal of Adolescence 32 (2009): 1209-23.

7. Kelly, Marguerite, Melanie J. Zimmer-Gembeck, and Marie Boislard-Pepin. "Identity, intimacy, status and sex dating goals as correlates of goal-consistent behavior and satisfaction in Australian youth." Journal of Adolescence 35 (2012): 1441-54.

8. Cantor, Nancy, and Catherine A. Sanderson. "The functional regulation of adolescent dating relationships and sexual behavior: An interaction of goals, strategies and situations." In Motivation and Self-Regulation across the Life Span. Edited by In Jutta Heckhausen and Carol S. Dweck. New York: Cambridge University Press, 1998, pp. 185-215.

9. Kelly, Marguerite, Melanie J. Zimmer-Gembeck, and Marie Boislard-Pepin. "Goals, behavior and satisfaction: The associations of sexual orientation and gender with identity, intimacy, status and sex." In Adolescent Behavior. New York: NOVA Science Publishers, 2012, pp. 71-94. 
10. Ott, Mary A., Susan G. Millstein, Susan Ofner, and Bonnie L. Halpern-Felsher. "Greater expectations: Adolescent's positive motivations for sex." Perspectives on Sexual and Reproductive Health 38 (2006): 84-89.

11. Zimmer-Gembeck, Melanie J., Nicole Hughes, Marguerite Kelly, and Jennifer Connolly. "Intimacy, identity and status: Measuring dating goals in late adolescence and emerging adulthood." Motivation and Emotion 36 (2012): 311-22.

12. Sanderson, Catherine A., and Sarah M. Evans. "Seeing one's partner through intimacy colored glasses: An examination of the processes underlying the intimacy goals-relationship satisfaction link.” Personality and Social Psychology Bulletin 27 (2001): 463-73.

13. Sanderson, Catherine A., Emily J. Keiter, Michael G. Miles, and Darren J. Yopyk. "The association between intimacy goals and plans for initiating dating relationships." Personal Relationships 14 (2007): 225-43.

14. Sanderson, Catherine A., and Nancy Cantor. "Social dating goals in late adolescence: Implications for safer sexual activity." Journal of Personality and Social Psychology 68 (1995): 1121-34.

15. Sanderson, Catherine A., and Nancy Cantor. "The association of intimacy goals and marital satisfaction: A test of four mediational hypotheses." Personality and Social Psychology Bulletin 27 (2001): 1567-77.

16. Zimmer-Gembeck, Melanie J., and Jillian Petherick. "Intimacy dating goals and relationship satisfaction during adolescence and emerging adulthood: Identity formation, age and sex as moderators." International Journal of Behavioral Development 30 (2006): 167-77.

17. Buss, David M. "Human mate selection: Opposites are sometimes said to attract, but in fact we are likely to marry someone who is similar to us in almost every variable." American Scientist 73 (1985): 47-51.

18. Miller, Lynn C. "Intimacy and liking: Mutual influence and the role of unique relationships." Journal of Personality and Social Psychology 59 (1990): 50-60.

19. Cantor, Nancy. "Life task problem solving: Situational affordances and personal needs." Personality and Social Psychology Bulletin 20 (1994): 235-43.

20. Gollwitzer, Peter M. "Goal achievement: The role of intentions." In European Review of Social Psychology. Edited by Wolfgang Stroebe and Miles Hewtone. New York: Wiley, 1993, pp. 141-85.

21. Mischel, Walter, Nancy Cantor, and Susan Feldman. "Principles of self-regulation: The nature of willpower and self-control." In Social Psychology: Handbook of Basic Principles. Edited by E. Tory Higgins and Arie W. Kruglanski. New York: Guilford Press, 1996, pp. 329-60.

22. Snyder, Mark, and William Ickes. "Personality and social behavior." In Handbook of Social Psychology, 3rd ed. Edited by Gardner Lindzey and Elliot Aronson. New York: Random House, 1985, pp. 883-948.

23. Swann, William B., Jr. "Identity negotiation: Where two roads meet." Journal of Personality and Social Psychology 53 (1987): 1038-51.

24. Collins, W. Andrew, and Stephanie D. Madsen. "Personal relationships in adolescence and early adulthood." In The Cambridge Handbook of Personal Relationships. Edited by Anita L. Vangelisti and Daniel Perlman. New York: Cambridge University Press, 2006, pp. 191-210. 
25. Fincham, Frank D., and Thomas N. Bradbury. "Social cognition in behavioral assessment and behavior therapy." In Handbook of Behavior Therapy and Psychological Science: An Integrative Approach. Edited by Paul R. Martin. New York: Pergamon Press, 1991, pp. 283-307.

26. Kurdek, Lawrence A. "Predictors of increases in marital distress in newlywed couples: A 3-year prospective longitudinal study." Developmental Psychology 27 (1991): 627-36.

27. Reis, Harry T., and Philip Shaver. "Intimacy as an interpersonal process." In Handbook of Personal Relationships: Theory, Research and Interventions. Edited by Steve Duck. Oxford, England: John Wiley and Sons, 1988, pp. 367-89.

28. Brunstein, Joachim C., Gabriele Dangelmayer, and Oliver C. Schultheiss. "Personal goals and social support in close relationships: Effects on relationship mood and marital satisfaction." Journal of Personality and Social Psychology 71 (1996): 1006-19.

29. Deci, Edward L., and Richard M. Ryan. Intrinsic Motivation and Self-Determination in Human Behavior. New York: Plenum, 1985.

30. Deci, Edward L., and Richard M. Ryan. "The 'what' and 'why' of goal pursuits: Human needs and the self-determination of behavior." Psychological Inquiry 11 (2000): 227-68.

31. Emmons, Robert A. "Personal strivings: An approach to personality and subjective well-being." Journal of Personality and Social Psychology 51 (1986): 1058-68.

32. Cantor, Nancy 'From thought to behavior: 'Having' and 'doing' in the study of personality and cognition.” American Psychologist 45 (1990): 735-50.

33. Emmons, Robert A., and Laura A. King. "Conflict among personal strivings: Immediate and long-term implications for psychological and physical well-being." Journal of Personality and Social Psychology 54 (1988): 1040-48.

34. Connell, James P., and James G. Wellborn. "Competence, autonomy, and relatedness: A motivational analysis of self-system processes." In Self Processes and Development: The Minnesota Symposia on Child Development. Edited by Megan R. Gunner and L. Allan Sroufe. Hillsdale, NJ: Lawrence Erlbaum, 1991, vol. 23, pp. 43-77.

35. Skinner, Ellen, Sandra Johnson, and Teresa Snyder. "Six dimensions of parenting: A motivational model." Parenting: Science and Practice 5 (2005): 175-235.

36. Ducat, Wendy H., and Melanie J. Zimmer-Gembeck. "Romantic partner behaviors as social context: Measuring six dimensions of relationships.” Journal of Relationships Research 1 (2010): 1-16.

37. Baumeister, Roy F., and Mark R. Leary. "The need to belong: Desire for interpersonal attachments as a fundamental human motivation.” Psychological Bulletin 117 (1995): 497-529.

38. Ryan, Richard M., Jennifer G. La Guardia, Jessica Solky-Butzel, Valery Chirkov, and Youngmee Kim. "On the interpersonal regulation of emotions: Emotional reliance across gender, relationships, and cultures.” Personal Relationships 12 (2005): 145-63.

39. Melanie J. Zimmer-Gembeck, and W. Andrew Collins. "Autonomy development during adolescence." In Blackwell Handbook of Adolescence. Edited by Gerald R. Adams and Michael Berzonsky. Oxford: Blackwell Publishers, 2003, pp. 175-204.

40. White, Robert W. "Motivation reconsidered: The concept of competence." Psychological Review 66 (1959): 297-333. 
41. Stewart, Stephanie, Heather Stinnett, and Lawrence B. Rosenfeld. "Sex differences in desired characteristics of short-term and long-term relationship partners." Journal of Social and Personal Relationships 17 (2000): 843-53.

42. Deci, Edward L., and Richard M. Ryan. "A motivational approach to self: Integration in personality." In Nebraska Symposium on Motivation. Lincoln, NE: University of Nebraska Press, 1991, pp. 237-88.

43. Bradbury, Thomas N., and Frank D. Fincham. "Individual difference variables in close relationships: A contextual model of marriage as an integrative framework." Journal of Personality and Social Psychology 54 (1988): 713-21.

44. Hendrick, Susan S. "A generic measure of relationship satisfaction.” Journal of Marriage and the Family 50 (1988): 93-98.

45. Skowron, Elizabeth A., and Anna K. Dendy. "Differentiation of self and attachment in adulthood: Relational correlates of effortful control." Contemporary Family Therapy 26 (2004): 337-57.

46. Skowron, Elizabeth A., and Myrna L. Friedlander. "The differentiation of self inventory: Development and initial validation.” Journal of Counseling Psychology 45 (1998): 235-46.

47. Connolly, Jennifer A., and Adele Goldberg. "Romantic relationships in adolescence: The role of friends and peers in their emergence." In The Development of Romantic Relationships in Adolescence. Edited by Wyndol Furman, B. Bradford Brown and Candice Feiring. New York: Cambridge University Press, 1999, pp. 266-90.

48. Noom, Marc J., Maja Deković, and Wim Meeus. "Conceptual analysis and measurement of adolescent autonomy." Journal of Youth and Adolescence 30 (2001): 577-95.

49. Rosenthal, Doreen A., Ross M. Gurney, and Susan M. Moore. "From trust to intimacy: A new inventory for examining Erikson's stages of psychosocial development." Journal of Youth and Adolescence 10 (1981): 525-37.

50. Zimmer-Gembeck, Melanie J., Wendy Ducat, and W. Andrew Collins. "Autonomy development during adolescence." In Encyclopedia of Adolescence. Edited by B. Bradford Brown and Mitchell Prinstein. London: Elsevier, 2012.

51. Berscheid, Ellen. "Love in the third dimension." Annual Review of Psychology 61 (2010): 1-25.

52. Gottman, John. M. "Psychology and the study of marital processes." Annual Review of Psychology 49 (1998): 169-97.

53. Watson, David, Brock Hubbard, and David Wiese. "Self-other agreement in personality and affectivity: The role of acquaintanceship, trait visibility, and assumed similarity." Journal of Personality and Social Psychology 78 (2000): 546-58.

54. Zimmer-Gembeck, Melanie J., and Wendy Ducat. "Positive and negative romantic relationship quality: Age, familiarity, attachment and well-being as correlates of couple agreement and projection." Journal of Adolescence 33 (2010): 879-90.

55. Arnett, Jeffrey J. "Emerging adulthood: A theory of development from the late teens through the twenties." American Psychologist 55 (2000): 469-80.

56. Kroger, Jane. "The status of identity: Developments in identity status research." In Adolescence and beyond: Family Processes and Development. Edited by Patricia K. Kerig, Marc S. Schulz and Stuart T. Hauser. New York: Oxford University Press, 2012, pp. 64-83. 
57. Deci, Edward L., and Richard M. Ryan. "Human autonomy: The basis for true self-esteem." In Efficacy, Agency, and Self-Esteem. Edited by Michael H. Kernis. New York: Plenum, 1995, pp. 31-49.

58. Diener, Ed, Eunkook M. Suh, Richard E. Lucas, and Heidi L. Smith. "Subjective well-being: Three decades of progress." Psychological Bulletin 125 (1999): 276-302.

59. Reiss, Steven, and Susan M. Havercamp. "Motivation in developmental context: A new method for studying self-actualization.” Journal of Humanistic Psychology 45 (2005): 41-53.

60. Ryan, Richard M., and Edward L. Deci. "Self-determination theory and the facilitation of intrinsic motivation, social development, and well-being." American Psychologist 55 (2000): 68-78.

61. Lucas, Richard E., and Portia S. Dyrenforth. "Does the existence of social relationships matter for subjective well-being?" In Self and Relationships: Connecting Intrapersonal and Interpersonal Processes. Edited by Kathleen D. Vohs and Eli J. Finkel. New York: Guilford, 2006, pp. 254-73.

62. Proulx, Christine M., Heather M. Helms, and Cheryl Bueler. "Marital quality and personal well-being: A meta-analysis.” Journal of Marriage and the Family 69 (2007): 576-93.

63. Reis, Harry T., W. Andrew Collins, and Ellen Berscheid. "The relationship context of human behavior and development.” Psychological Bulletin 126 (2000): 844-72.

64. Kenny, David A., Deborah A. Kashy, William L. Cook, and Jeffry A. Simpson. Dyadic Data Analysis. New York: Guilford, 2006.

65. Zirkel, Sabrina, and Nancy Cantor. "Personal construal of life tasks: Those who struggle for independence.” Journal of Personality and Social Psychology 58 (1990): 172-85.

(C) 2014 by the authors; licensee MDPI, Basel, Switzerland. This article is an open access article distributed under the terms and conditions of the Creative Commons Attribution license (http://creativecommons.org/licenses/by/3.0/). 